\title{
APPLICATION OF IMPROVED ACCURACY SFM-MVS FOR PHOTOGRAMMETRIC RESTITUTION AND COMPARISON OF PRE- AND POST-ERUPTION ARCHIVAL AERIAL IMAGERY ON DECEPTION ISLAND (SOUTH SHETLAND, ANTARCTICA)
}

\author{
APLICACIÓN DE SFM-MVS CON PRECISIÓN MEJORADA PARA LA RESTITUCIÓN FOTOGRAMÉTRICA Y \\ COMPARACION DE LAS IMÁGENES AÉREAS DE ARCHIVO PRE Y POST ERUPCION \\ EN ISLA DECEPCIÓN (SHETLAND DEL SUR, ANTÁRTIDA)
}

\author{
Carlos Paredes ${ }^{\mathrm{a},{ }^{*},}$ Rogelio de la Vega-Panizo ${ }^{\mathrm{a}}$, Miguel Ángel Ropero ${ }^{\mathrm{a}, \mathrm{b}}$ \\ a Department Geological \& Mining Engineering, E.T.S.I. de Minas y Energía, Universidad Politécnica de Madrid, C/ Ríos Rosas 21, \\ 28003 Madrid, Spain. carlos.paredes@upm.es; rogelio.delavega@upm.es; miguelangel.ropero@alumnos.upm.es

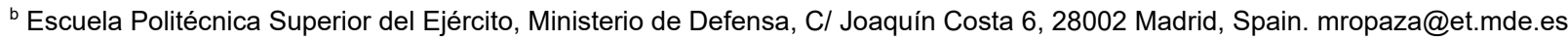

\begin{abstract}
:
Despite today's extensive remote sensing imagery with all kinds of sensors, the use of old aerial imagery is still important in the study of slowly evolving land processes to reconstruct past landscape forms. Numerous organisations share photogrammetric data in public repositories, offering opportunities to exploit them to identify historical, natural and anthropogenic topographic changes, which is particularly interesting if they are difficult to access areas, possibly affected since historic times by climate change and other geodynamic processes. This work proposes and applies a workflow based on the SfM-MVS photogrammetric technique to 22 and 33 historical aerial photographs of the English FIDASE (1956/57) and Argentinean Navy (1968) flights, scanned at 1016dpi and 96dpi, black and white, of Deception Island (South Shetland, Antarctica). The photogrammetric processing controls the threshold values of the reconstruction uncertainties and projection accuracy. The 3D point clouds obtained are geroreferenced with 37 ground control points (GCP) geographically positioned in a QuickBird2 satellite image over island areas not affected by volcanism. The quality of the DTM is controlled by comparison with the 1960 topographic map 1:25000 of the island, which allows the volumes of material emitted in the volcanic eruption of 1967 to be evaluated. The results obtained improve considerably and extend the set of results compared to those obtained by classical contour line digitizing. The applied method, the DTM and orthomosaic of 1956 and 1968 presented will allow us to evaluate, together with the analysis applied to later historical flights, English 1979 and Chilean 1986, the recent changes produced by the recent volcanism, the local external geodynamics, the possible climatic deterioration and the scope of current human activity from 1956 to the present day.
\end{abstract}

Key words: Deception Island, photogrammetry, structure from motion, archival imaging, volcano, digital elevation model

\section{Resumen:}

A pesar de la actualmente minuciosa toma de imágenes con sensores de todo tipo, la utilización de antiguas imágenes aéreas sigue siendo importante en el estudio de procesos del terreno de evolución lenta para reconstruir las formas pasadas del paisaje. Numerosas administraciones comparten los datos fotogramétricos en depósitos públicos, ofreciendo oportunidades para explotarlos y detectar cambios topográficos históricos naturales y antropogénicos, lo cual resulta ser de mayor interés si son zonas de difícil acceso, posiblemente afectadas desde tiempos pretéritos por el cambio climático y otros procesos geodinámicos. Este trabajo, propone y aplica un flujo de trabajo basado en la técnica fotogramétrica SfMMVS a 22 y 33 fotos aéreas históricas de los vuelos inglés FIDASE (1956/57) y de la Armada Argentina (1968), escaneadas a 1016ppp y 96ppp, en blanco y negro, de la Isla Decepción (Shetland del Sur, Antártida). El procesado fotogramétrico controla los valores umbral de las incertidumbres de la reconstrucción y precisiones de proyección. Las nubes de puntos 3D obtenidas son gerorreferenciadas con 37 puntos de control terrestre (GCP) geográficamente posicionados en una imagen QuickBird2 sobre zonas no afectadas por vulcanismo. La calidad de los MDE se controla comparándolo con el mapa topográfico 1:25000 de la Isla lo que permite evaluar los volúmenes de material emitido en la erupción volcánica de 1967. Los resultados obtenidos mejoran notablemente y extienden el conjunto de resultados frente los obtenidos por digitalización clásica de las curvas de nivel. El método aplicado, los MDE y ortomosaico de 1956 y 1968 presentados permitirán evaluar, junto con el análisis aplicado a vuelos históricos posteriores, inglés de 1979 y chileno de 1986, los cambios recientes producidos por el volcanismo reciente, la geodinámica externa local, el posible deterioro climático y ámbito de afección de la actividad humana actual desde 1956 hasta la actualidad.

Palabras clave: Isla Decepción, fotogrametría, structure from motion, imágenes históricas, volcán, modelo digital elevaciones 


\section{Introduction}

The Spanish Army Antarctic Base "Gabriel de Castilla" (BGdC) is located on Deception Island (South Shetland Islands, Antarctic Peninsula, Antarctica). The uniqueness of its location responds to the special scientific interest it arouses from multiple fields of knowledge (Baker et al. 1975). The fact that man has established a temporary settlement on the island and its interaction with the natural environment, the scene of multiple geo-hydrodynamic processes that pose a certain hazard, opens up the possibility of other problems of particular relevance. Its studies, conclusions, and recommendations give rise to reflections on the most appropriate way in which human activity should be carried out in these latitudes in a sustained manner, mitigating the effects of the same (LIERopero 2015). Deception Island is the most active volcano in the South Shetland Islands and has been the site of more than twenty identified eruptions in the last two centuries (Berrocoso et al. 2012). Recent eruptions $(1967,1969$, and 1970) have demonstrated that the island can become a significant potential hazard to tourists (over 30000 visits in the austral summer), scientists, and military personnel on and around the island (Fig. 1). In addition, each volcanic event has caused significant uplift or subsidence, ground displacement or infilling of deposits, and changes in the island's relief and coastline.

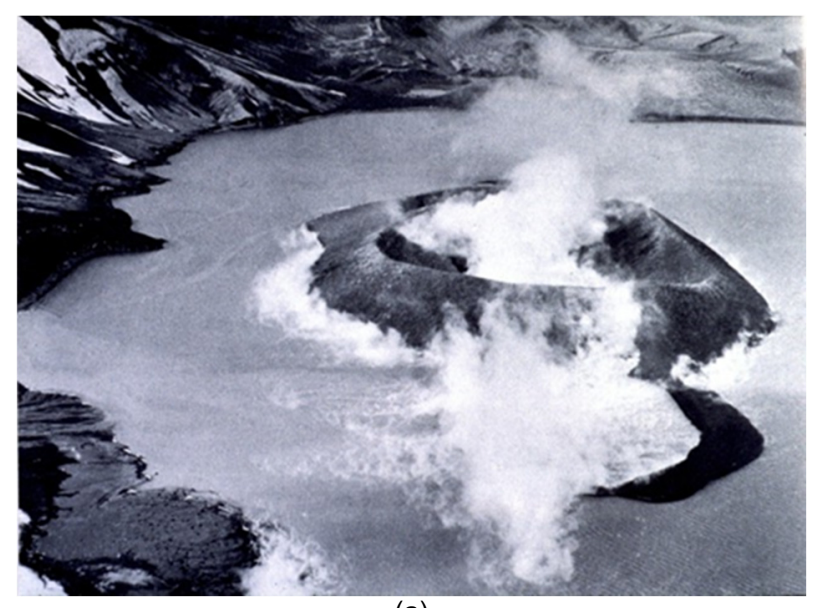

(a)

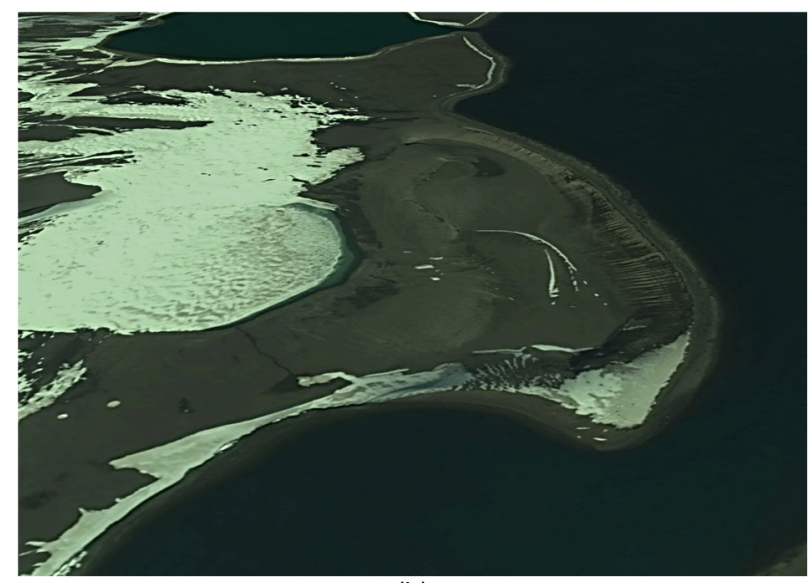

(b)

Figure 1: View of Yelcho Island (a) formed after the December 1967 eruption and joined to Deception Island (b) after the August 1970 eruption to form the current landscape.
Since the beginning of the 20th century, aerial photo techniques and photogrammetry have been used in earth sciences to remotely define characteristics and geometric properties of objects from photographs. Currently, modern techniques of image analysis and machine learning, developed in the field of $3 D$ artificial vision (Ullman 1979; Hartley and Zisserman 2004), have been applied to UAV flight photogrammetry such as SfM-MVS (structure from motion - multiview stereo) methodology, multiplying the processing capacity, beyond the stereoscopic pair, to the massive use of images of different origin and quality, obtaining results comparable to LIDAR. Its versatility makes it possible that many of the archived historical flights, an important reference record, especially in sparsely populated or very difficult to access areas, such as the Arctic or Antarctica, subject to geological or anthropogenic climate changes, can be scanned, reviewed and re-analysed with SfM-MVS.

The historical record of changes on Deception Island has made it possible to quantify them using classical methods of digitizing and interpolation of existing cartography (Berrocoso et al. 2012; Torrecillas et al. 2012). However, these approximations are strongly conditioned by the resolution, quality, and historical processing methods of the available topographic data. This paper proposes a standard procedure for SfM-MVS restitution of historical flights, with uncertainty control and georeferencing to terrain, as an alternative to classical stereo photogrammetric techniques when camera data or images are incomplete or missing, which is common in old imagery of remote places, to obtain a DTM and an orthoimage. The derived products will make it possible to quantify in detail, and with less error than the data currently available, the variations of the terrain, providing qualitative historical information on the geomorphological evolution of the surface of Deception Island.

\section{Study area: the Deception Island}

Deception Island is the southernmost island of the South Shetland Archipelago in the South Atlantic. It lies between latitudes $62^{\circ} 53$ ' $30^{\prime \prime} S$ and $63^{\circ} 01^{\prime} 20^{\prime \prime} S$, and longitudes $60^{\circ} 29$ '20" W and $60^{\circ} 45^{\prime} 10^{\prime \prime} \mathrm{W}$, in the Bransfield Strait, approximately $25 \mathrm{~km}$ south of Livingston Island, $100 \mathrm{~km}$ north of the Antarctic Peninsula, and about $1000 \mathrm{~km}$ from Tierra del Fuego, at the southern tip of the South American continent (Fig. 2a). It is a horseshoe-shaped island, with an outer perimeter of approximately $18 \mathrm{~km}$ in diameter. Today, the overall appearance of the island is strongly influenced by the collapse of the volcanic caldera at its centre (about $8.300-3.980 \mathrm{y}$ ) as well as by the latest volcanic eruptions that have occurred since the 18th century. The inner coast, accessed by crossing Neptune's Bellows Pass to the south, is called Port Foster. An almost complete ring of post-caldera volcanic edifices, hills, and mountains surrounds this inner bay (Fig. 2b).

The remnants of the collapsed volcanic complex are covered by glaciers and reach $539 \mathrm{~m}$ a.s.l. at Mount Pond and $452 \mathrm{~m}$ a.s.I. at Mount Kirkwood. To date, more than 20 explosive monogenetic eruptive events have been identified over the last two centuries. Throughout these events, several cinder cones and volcanic edifices have developed, such as Crimson Hill (between 1825 and 1829) and Kroner Lake (between 1829 and 1912) and the 1967, 1969 and 1970 eruptions, which are the most recent landscape modifications. Today, the island is home 
to the Argentinean Antarctic Base Decepción and the $\mathrm{BGdC}$, whose activity is restricted to the southern summer (Fig. 2b). Even today, geothermal and seismic activity persists, as well as other active geomorphological processes (Baker et al. 1975; LIE-Ropero 2015).

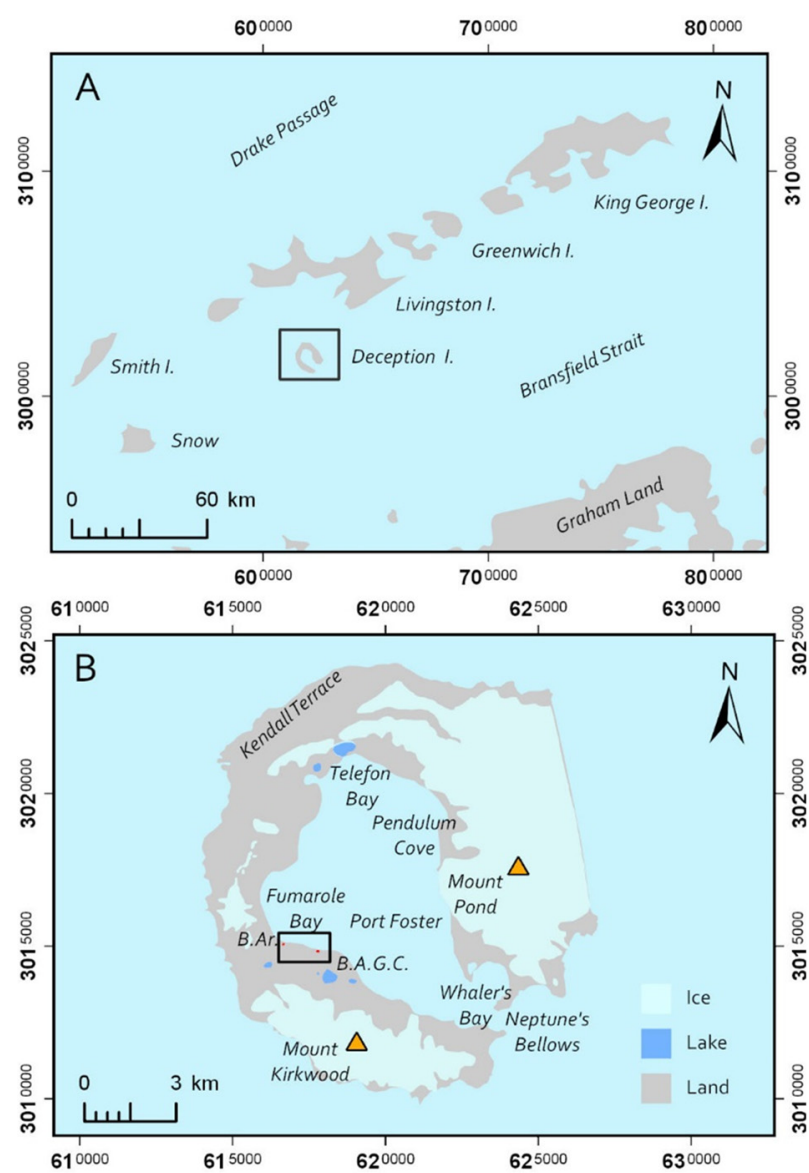

Figure 2: Geographical location of Deception Island (a) in the South Shetland Islands Archipelago and (b) the island toponyms used in the text. In the inset, the area in which the Argentine Deception and Spanish BGdC bases are located.

\section{Satellite, archive aerial imaging and maps datasets}

Three main sources of spatial data covering the study area were used to carry out this work. Aerial images set taken during the $1955 / 56$ and $1956 / 57$ campaigns of the FIDASE project. Aerial images set taken by the Argentinean Navy in 1968 (after the 1967 eruption). And a topographic map 1:25000 produced by the Directorate of Overseas Surveys in 1960, resulting from the photogrammetric restitution work of the FIDASE flights. In addition, the satellite QuickBird2 (QB2) multispectral image was acquired in 2003 (Table 1).

The Falkland Islands Dependencies Aerial Survey Expedition (FIDASE) acquired in 1956-1957 the first systematic vertical aerial photography and ground survey for photogrammetry for the north-western part of the Antarctic Peninsula (Mott 1986), covering an area of about $15,000 \mathrm{~km}^{2}$, between $62^{\circ}$ and $68^{\circ} \mathrm{S}$ latitude, and using as a base and port, for the ships and two Canso hydroplanes of Hunting Aerosurveys Ltd., the harbour at Whalers Bay in Port Foster. The photography was taken at a customary altitude of approximately 13,500 feet and was planned for photogrammetric mapping with $60 \%$ overlap and $30 \%$ sideslip with a Williamson Eagle IX $f=$ $152 \mathrm{~mm}$ camera, with the Ross 6" lens on a 9" format negative. Stop F.II was used throughout with a normal exposure time of $1 / 200$ second, although in the latter part of the season this was increased to just 1/50 second. The entire mission was conducted on Ilford Hyperpan film using a blue negative filter (comparable to the Wratten $G$ ). The available FIDASE expedition photographs of Deception Island are spread over two passes of 31 and 22 images, taken at $3962 \mathrm{~m}, 1: 26000$ and $4390 \mathrm{~m}$, 1:28800 respectively and were supported by 8 astronomically triangulated surface points and supported by the nearby islands of the Shetland Archipelago. The 1016 ppp images (10002x10002 px) from both flights are available and documented on the USGS earthexplorer website. Post-processing of the FIDASE expedition flights enabled the mapping of many previously unexplored or inaccessible areas around the Antarctic Peninsula to be produced stereo-photogrammetrically.

Table 1: Characteristics of image acquisition flights.

\begin{tabular}{c|c|c} 
Flight survey data & $\begin{array}{c}\text { FIDASE Hunting UK } \\
1956\end{array}$ & $\begin{array}{c}\text { Argentinean } \\
\text { Army 1968 }\end{array}$ \\
\hline Flying altitude & $5650 \mathrm{~m}$ & $4650 \mathrm{~m}$ \\
Scale & $1: 28800$ & $1: 30000$ \\
Camera model & Williamson Eagle IX & $\mathrm{K}-176 "$ \\
Focal length & $152 \mathrm{~mm}$ & $152.4 \mathrm{~mm}$ \\
Coverage area & $274 \mathrm{~km}^{2}$ & $244 \mathrm{~km}^{2}$ \\
Scan resolution & $9761 \times 9868$ & $5400 \times 5400$ \\
Av.ground res. & $0.773 \mathrm{~m} / \mathrm{px}$ & $1.21 \mathrm{~m} / \mathrm{px}$ \\
No. photo scanned & 22 & 33 \\
No. of flight tracks & 3 & 4
\end{tabular}

During the Antarctic campaign in the summer of 1947/48, the Argentine Navy, with the presence of five ships, inaugurated the Caleta Péndulo refuge in Puerto Foster (Nov. 1947) and the Destacamento Naval Decepción (Jan. 1948) in Fumarolas Bay, repaired and installed a series of beacons (Grumete and unnamed) and carried out an unavailable aerophotogrammetric survey of the island. After the eruption of December 1967, on 21 January 1968, the Argentine Navy conducted a reconnaissance flight to support the analysis of the changes produced on the island after the eruption. The flight was scheduled at an average altitude of $4500 \mathrm{~m}$ with a shooting scale of $1: 30000$ and a longitudinal overlap of $60 \%$ and a lateral overlap of less than $20 \%$. The 33 images were taken with a K17 camera of 6" focal length $(152.4 \mathrm{~mm})$ distributed in four passes, three N-S, two with 9 overlapping, and one with 8 photos, and one NW-SE, with seven photos, which were scanned nonphotogrammetrically at a size of $5400 \times 5400$ px at $96 \mathrm{dpi}$. No additional information is available on the photos or on the camera calibration parameters.

The topographic map of Deception Island, Falkland Islands Dependencies, South Shetland Islands, Directorate of Overseas Surveys (1960) sheet D.O.S. 310 , is a product obtained from the FIDASE flight. It is a printed version map 2,250/8/60/6175/O.S., scale of $1: 25000$, altimetry in feet with a separation of 50 feet between contour lines, and in Lambert Conic 
Orthomorphic projection, $70^{\circ}$ South latitude from the origin, where the scale factor is 0.9931 and the Clarke 1880 spheroid. Although in 1957, Hunting Aerosurveys Ltd. established eight survey points on Deception Island for the production of the island map, none of them are in suitable locations to orient the stereoscopic models covering the area mapped in this work. The 18 astronomical survey points established (Hydrographic Department Admiralty 1949) are also unusable because they are either lost, unidentifiable or not in a suitable location.

Due to the lack of ground control points in both flights, a multispectral image from the QuickBird 2 DigitalGlobe satellite (Fig. 1c) of 21 January 2003, with no cloud cover over the island, at an average resolution of $0.68 \mathrm{~m} / \mathrm{px}$ and with an orientation of $14.6^{\circ}$ off-nadir angle and a solar height of $37.9^{\circ}$ in the east, has been taken as a real ground reference. In this image, 37 ground control points (GCP), with their planimetric coordinates in WGS 84 / UTM zone 20S (EPSG::32720), have been taken at permanent locations (Fig. 3): rocky promontories on the coast and inland, with an estimated error of $0.68 \mathrm{~m}$.

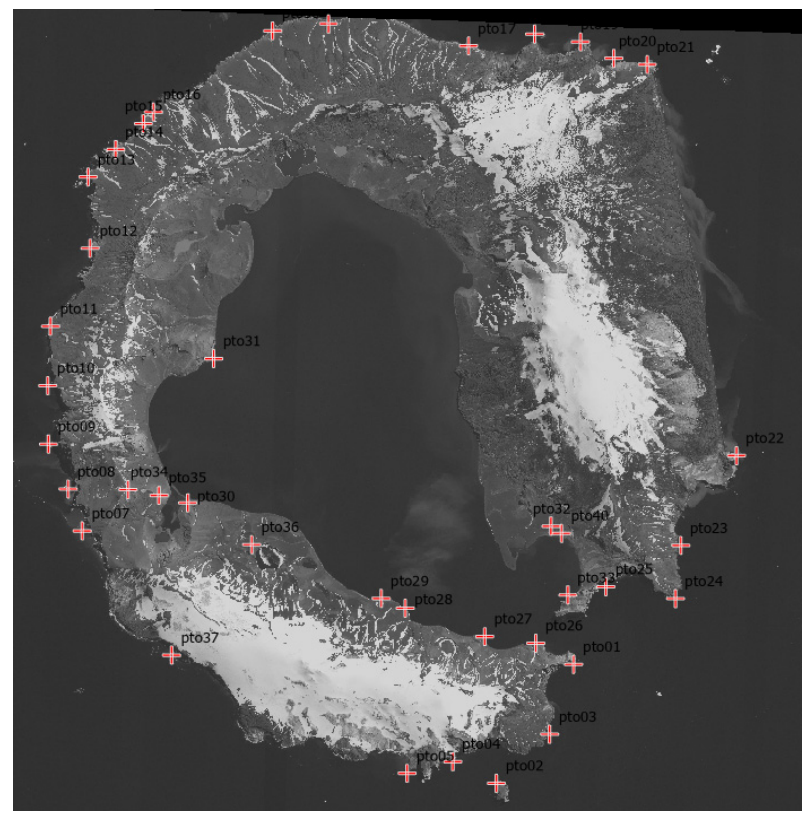

Figure 3: Geographical distribution of the $37 \mathrm{GCP}+$ on Deception Island QB2 image.

These points must be detectable in the images of the 1956 and 1968 flights and in the QB2 image, and their position must not be affected planimetrically or altimetrically by the volcanism of the island to date. Finally, the map D.O.S. (1960) has been scanned at 300 dpi, 24 bits, reprojected to UTM WGS84, geometrically readjusted with a 2 nd order polynomial transformation and georeferenced to the QB2 satellite image taken as ground reality.

\section{Workflow methodology}

The aim of this work is to obtain a series of digital products from historical images with sufficient quality for the identification of geomorphological processes active at the time, and the quantitative treatment of their geospatial information. To this purpose, a photogrammetric restitution scheme of the images has been established, which can be summarised as follows. a) Scanned images pre-processing to identify and discard those of poor quality, adjust sharpness, locate their centres and the GCPs. b) SfM camera orientation processing, optimisation of camera parameters, considering the reduction of reconstruction uncertainty, reprojection error, and improving projection accuracy, to obtain the 3D sparse point cloud (3DSPC). c) SfM-MVS with the 3DSPC georeferenced to the GCPs to obtain the 3D dense point cloud (3DDPC) and depth maps. After this error minimisation processing, the triangulation irregular network (TIN), the DTM, and the orthomosaic of the images are obtained. Finally, d) the quality of the products is evaluated by comparing the global location errors of the images, the GCP, planimetry, and altimetry of the 1:25000 map of 1960, with the coastline and rocky outcrops of the QB2 image unaffected by the eruptions. Some recent works (USGS James 2017; Mayer et al. 2018; Girod et al. 2018; Riquelme et al. 2019, among others) present a sequential workflow that attempts to standardise the process on Agisoft Metashape even for historical image processing, however, the authors present differences in the guidelines and the results they show do not establish or value a quantitative quality criterion for the final products (Singh and Fraizer 2018). Therefore, this work incorporates an improvement (Fig. 4) of the 3DSPC to be used for the MVS algorithm and to obtain the 3DDPC, gradually selecting the points with the worst estimation in terms of different projection errors, optimising sequentially each improvement.

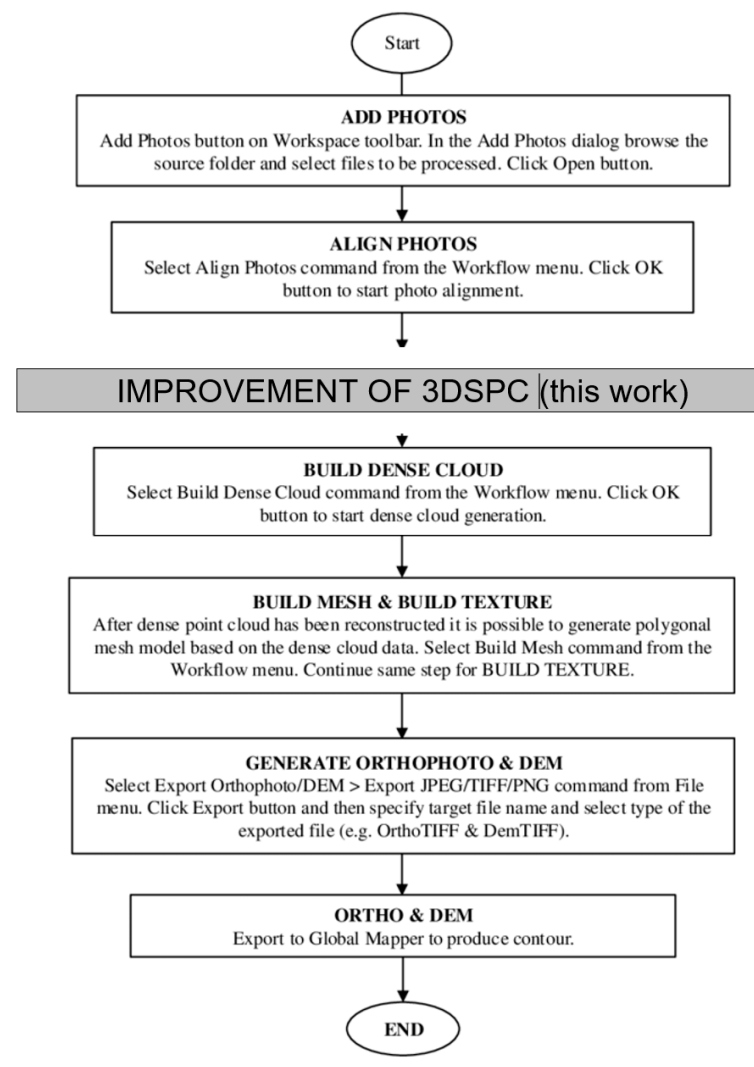

Figure 4: Standard Sfm-MVS flowchart for aerial image processing with the contribution of this work.

Nowadays, there is a wide range of software applications that implement SfM-MVS techniques (Metashape, Pix4D, Photomodeller Scanner, OpenDroneMap, etc.), in this work Metashape 1.6.5. from Agisoft LLC is used as it 
enables full restitution processing with operator intervention and control, and uses cameras and images with very little metadata.

\subsection{Pre-processing, orientation and alignment}

The stereographic restitution process is strongly conditioned by the quality and orientation of the images taken over the object or area of interest. The contrast, brightness, and sharpness conditions should be as close as possible to the shape, and width of the histogram: uniform, without change by zones, and full band. Therefore, the first step is to check the quality of the images, discard those with clouds covering the areas of interest, readjust their histogram if necessary, and apply reject masks for areas of no interest (sea, clouds...) or difficult to link stereo pairs.

The alignment of the photos is then performed by SfM, discarding the position of the GCPs. The procedure automatically detects the tie points (TP) by coincidence of images, matching in which each TP appears, obtaining the 3DSPC, returning the parameters of interior and exterior orientation of all images, the systematic compensation of errors and distortions of the camera lenses. The orientation of the cameras through the adjustment of the 8 parameters $\mathrm{f}, \mathrm{cx}, \mathrm{cy}, \mathrm{k} 1, \mathrm{k} 2, \mathrm{k} 3, \mathrm{p} 1$, $\mathrm{p} 2$, considers that, during the flight, there were oscillations in the shots of up to $10^{\circ}$ due to the wind streams that hit the aeroplane, which could also generate a rolling shutter effect (Mott 1986).

\subsection{Error reduction over 3DSPC}

Possible non-linear deformations from the former preprocessing can be eliminated by optimising the camera parameters on the basis of the known reference coordinates of the photos. For this purpose, the coordinates of the 3DSPC points and the camera parameters are adjusted by minimising the sum of the reprojection errors and the misalignment error of the reference coordinates. To achieve better results, a maximum of $10 \%$ to $20 \%$ of the misallocated 3DSPC points are removed and the camera parameters ( $\mathrm{f}, \mathrm{cx}, \mathrm{cy}$, $\mathrm{k} 1, \mathrm{k} 2, \mathrm{k} 3, \mathrm{p} 1, \mathrm{p} 2)$ are re-optimised iteratively, until the reconstruction uncertainty $\mathrm{RU}<10$. This process is carried out in an analogous way to achieve a projection accuracy $P A<3-10$. Thus, the less reliable joint points with poor $3 \mathrm{D}$ point determination relative to the strongest ones are eliminated. Throughout the optimisation process, in addition to controlling the number of points that are eliminated due to poor estimation, we try to reduce the mean square error of the image localisation RMSE, maintain a high number of projections on these (above 120) and reduce the values of the covariance of the points of the 3DSPC.

After several iterations (usually less than 10), and obtaining a value close to 1.0 for the standard error of unit weight (SEUW) in the optimization process, the orientations, and camera parameters ( $f, c x, c y, k 1, k 2, k 3$, $\mathrm{k} 4, \mathrm{~b} 1, \mathrm{~b} 2, \mathrm{p} 1, \mathrm{p} 2, \mathrm{p} 3, \mathrm{p} 4)$ are re-computed restricted to the accuracy of the tie points. The tie point accuracy parameter depends on the image quality, as the tie point positions are estimated based on the significant features encountered in the images. If the images are sharp, the tie points are located accurately and the default value of
1.0 pixels may represent too small a weight. Precision values and weights work inversely: the higher the precision, the higher the weight. A precision of about 0.5 pixels is more realistic for identifying features well recognisable by a human operator in flight imagery.

\subsection{Dense geo-referenced photogrammetric processing}

To georeference the 3DSPC, when accurate navigation and location data are not available for many images, a feasible but appropriate number and spatial distribution of GCPs must be chosen. In this work, the block of aerial images oriented in the previous step is georeferenced using the 37 GCPs that have been identified in QB2 and that have been located on each of the photographs. In this step, the set of images and the 3DSPC are reprojected to the ground truth.

Next, the orientations and the 13 camera parameters ( $f$, cx, cy, k1, k2, k3, k4, b1, b2, p1, p2, p3, p4) are reoptimised conditional on the location of the 37 GCPs and a SEUW close to 1.0 is achieved. Finally, points with large residuals are selected in the georeferenced 3DSPC according to their reprojection error (RE), given in pixel units, which indicates poor 3D point determination of the corresponding point projections, as well as erroneously coincident points. Following an iterative process, a maximum of $10 \%$ to $20 \%$ of the 3DSPC points with a high reprojection error are removed and the camera parameters (f, cx, cy, k1, k2, k3, p1, p2) are re-optimised iteratively, until the reprojection error $\mathrm{RE}<1 \mathrm{px}$. The $\mathrm{RE}$ parameter has a more direct influence on the RMSE of the control points and can significantly improve the orientation parameters.

\subsection{Quality control assessment}

The use of photogrammetry, in its analogue beginnings, to obtain a cartographic representation of topography, used stereographic pairs of images taken in aerial missions that had to be meticulously programmed and carried out if a quality product was desired, with very low tolerances in the flight suitability parameters. These "historical" products are now reused by digitising them to obtain a digital terrain elevation model (DTM) of the past using modern interpolation techniques on the digitised point cloud in a GIS. Considering the quality for $1: 25000$ maps, the accuracy of DTM planimetry is of the order of 3 to $4 \mathrm{~m}$ according to the Koppe tables, i.e., the reference value that would prove this is, for example, the graphic accuracy of $0.2 \mathrm{~mm}$ in $1: 25000$ is $5 \mathrm{~m}$ on the ground, where the accuracy according to Koppe is below $5 \mathrm{~m}$. For altimetry, the accuracy depends on the fidelity of the representation of the relief according to contour curves and ground support points. The mean square errors of contour line positions, which determine the height accuracy, are commonly used as an elevation indicator of the accuracy of classical topographic maps, as well as the mean square errors of height points in relation to the nearest geodetic control points. Otherwise, this mean square error is given by the $\pm 0.2 \%$ of the flight height which, for the flights examined, is about $10 \mathrm{~m}$.

Since this work has employed massive image processing using the SfM-MVS technique, in addition to considering the planimetric and altimetric qualities of the resulting products, such as the DTM, the derived topographic map, 
and the orthoimage, it is necessary to take into account the different errors committed and their significance to assign an appropriate threshold to each one, following the workflow presented in Figure 5.

The reconstruction uncertainty is the ratio of the semimajor axis to the semi-minor axis of the error ellipse of the 3D triangulated point coordinates. By taking a criterion value of less than 10 , the tie points in image margin areas and points in models with a low base/height ratio, i.e., less than 1:2.3, are filtered out. The removal of these points does not affect the accuracy and does lighten the 3DSPC.

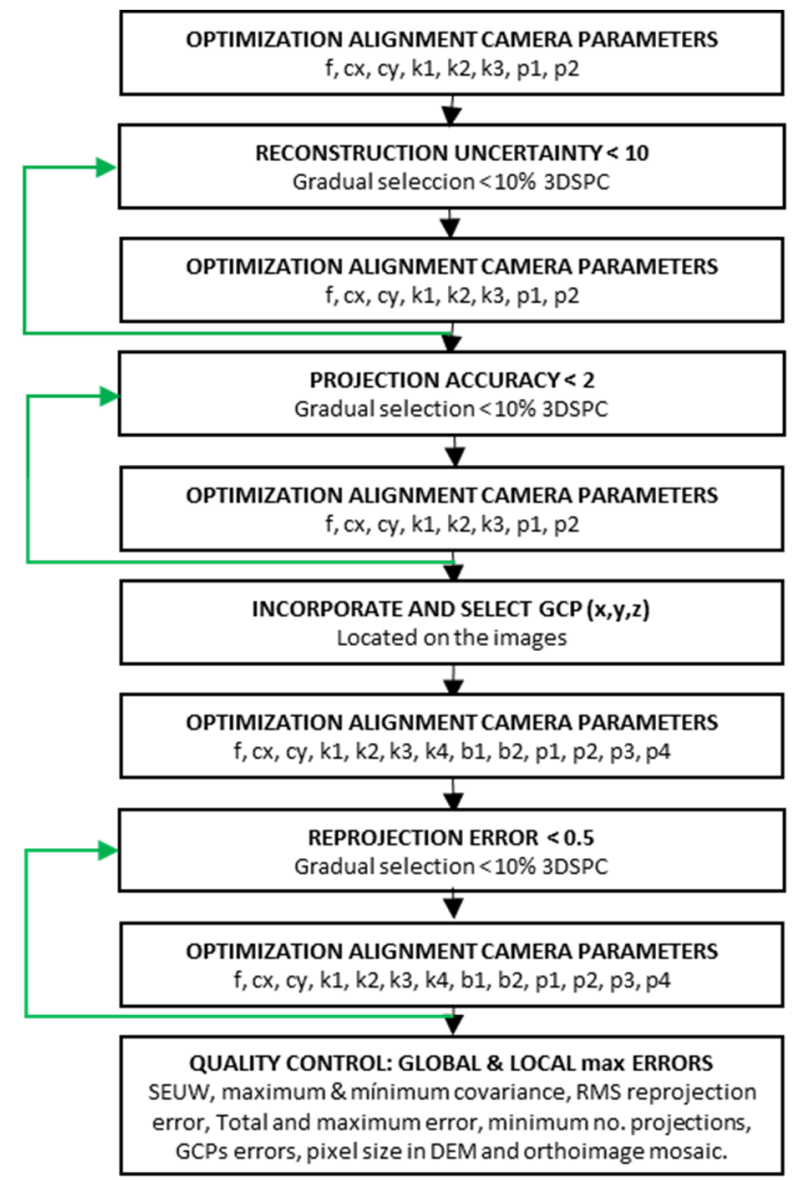

Figure 5: Development of the module Improvement of 3DSPC in Figure 4.

As the projection accuracy is the average scale of the image at which the image coordinates of the tie point were measured, imposing PA $<2$ has filtered out points with less localised projections due to the larger size. That is, eliminating the less reliable tie points with poor 3D point determination relative to the stronger ones.

The high reprojection error evaluated in pixels indicates poor 3D point determination of the corresponding point projections as well as erroneously matched points, i.e., poor localisation accuracy of the corresponding point projections in the point matching step. The elimination of points with high reprojection error can improve the accuracy of the subsequent optimisation step. A tie point reprojection error of 0.3 to 0.5 pixels is possible in the case of sharp images.

The fact that the values of each of the errors below the established thresholds $\mathrm{RU}<10, \mathrm{PA}<10, \mathrm{RE}<1.0$ have been achieved, ensures an adequate quality for the processing of the 3DSPC and the obtaining of the 3DDPC and depth maps. According to the flowchart in Figure 4, the triangulation irregular network (TIN) and the DTM and the have been obtained by means of the depth maps; the computed orthomosaic uses the obtained DTM. All products are referenced to the coordinate system in WGS 84 / UTM zone 20S (EPSG::32720).

\section{Results}

We selected for the FIDASE flight 22 images of the second pass (taken on 19/12/1956) covering an area (Fig. 6a) of $263 \mathrm{~km}^{2}$, neglecting those of the first track $(17 / 12 / 1956)$ because they had cloudy areas and an uncovered zone between Morro Baily and Punta SouthEast. Photocentre coordinates (EPSG::4326) and flying altitude from the USGS flight database have been directly incorporated in the image reference list. The histogram of the 22 images has been equalized with $200 \%$ brightness and $44 \%$ contrast. The image qualities are between 0.85 and 0.96 , higher than 0.7 as USGS recommend.

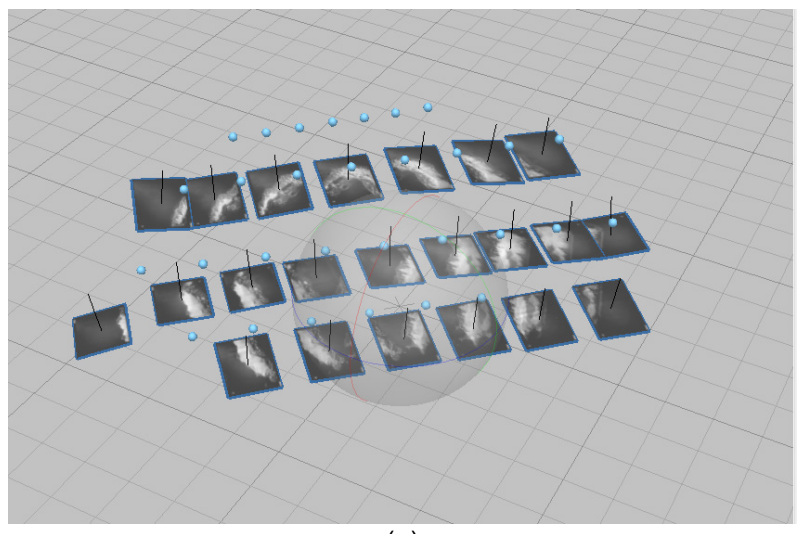

(a)

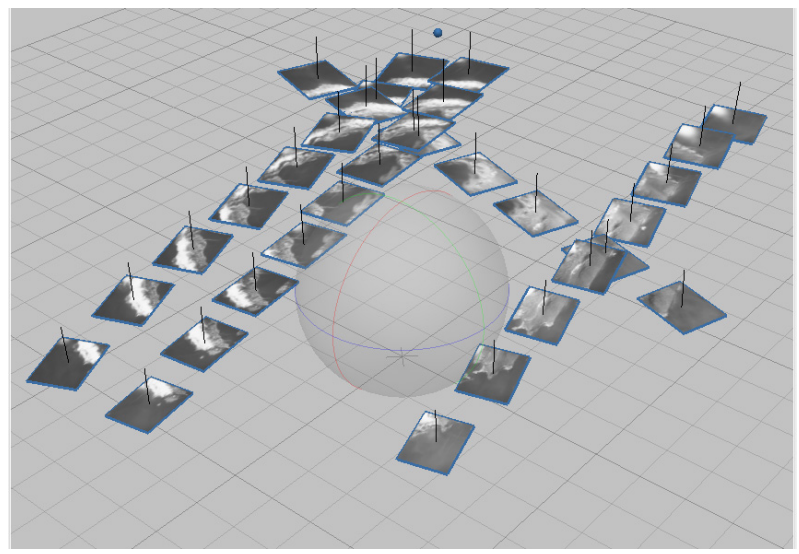

(b)

Figure 6: Relative location of images from: a) FIDASE; b) Argentinean photogrammetric flights.

The 33 images of the Argentinian flight (Fig. 6b) have a worse quality, between 0.81 and 0.53 . We have tried to correct the histogram by taking $140 \%$ for brightness and $57 \%$ for contrast, slightly improving its sharpness for the key and tie point image matching process. The coordinates (EPSG::32720) of the 37 GCPs are also incorporated, identifying them manually in the 22 and 33 images of each flight. 
The alignment of the photos is then performed by SfM, discarding the position of the GCPs, just considering the images from the FIDASE flight. However, in the case of Argentinean flight, the GCPs had to be used in conjunction with the images to obtain a first approximation of the photocentres that will then be used to complete the reference list of the images as well as the flight altitude. Once the image references of both flights have complete data ( $X_{\text {east }}, Y_{\text {north, }} Z_{\text {altitude }}$ ), the SfM algorithm is used, discarding the GCP to obtain the 3DSPC and the interior and exterior orientation of the images and optimisation of the camera parameters.

Next, the Sfm procedure automatically detects the tie points (TP) by coincidence of images, matching in which each TP appears, obtaining a preliminary 3DSPC for FIDASE and Argentinean flights. Using the proposed working scheme, within the standard Sfm-MVS photogrammetric restitution scheme (Fig. 4), which incorporates error reduction (Fig. 5), the quality 3DSPCs have been improved. The effect caused by the imposition of a certain threshold value on the projection accuracy and reprojection errors, does not only imply a censoring of the maximum value but, as shown in the empirical cumulative distribution functions (Fig. 7), a readjustment of all its values on the 3DSPC. This is due to the successive optimisations of the alignment and orientation of the cameras after each filtering.

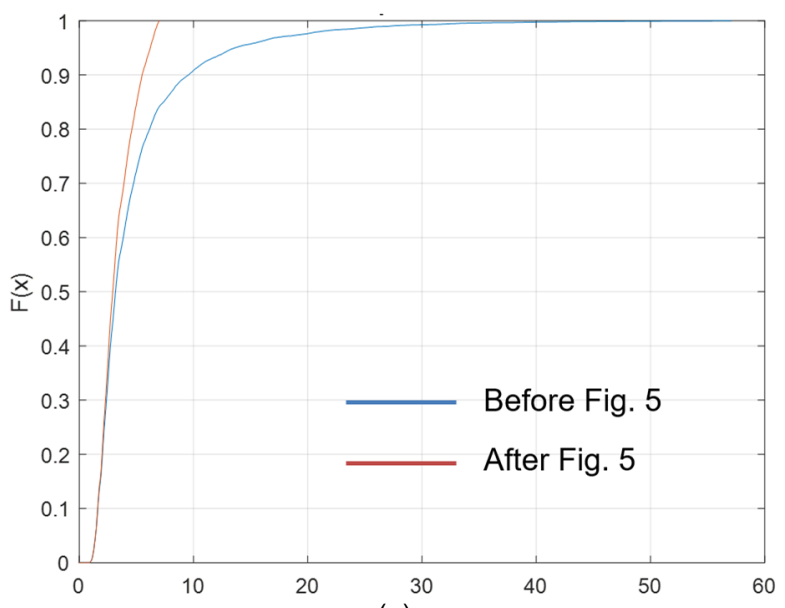

(a)

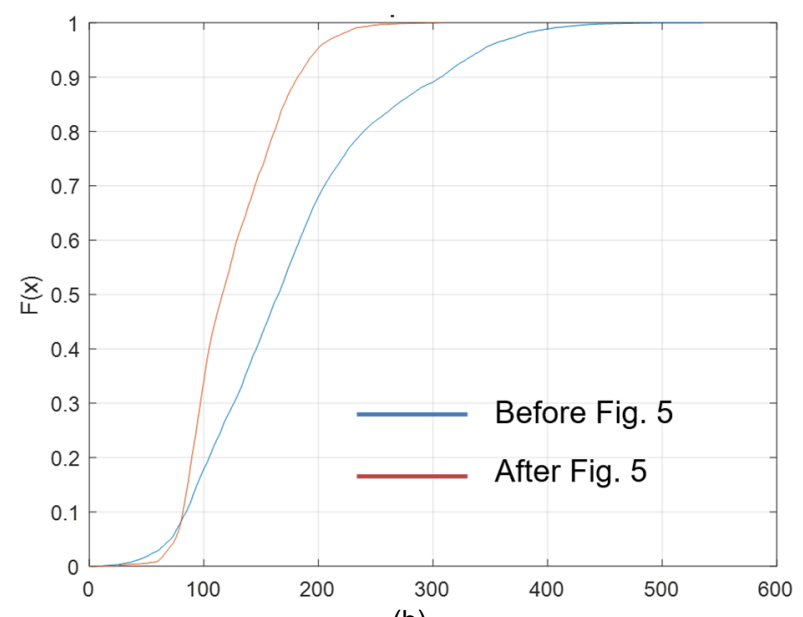

(b)

Figure 7: Variation of the empirical cumulative distribution functions after improvement of the projection accuracy and reprojection error of the 3DSPC of the FIDASE flight: a)

Projection accuracy; b) Absolute reprojection error.
The camera calibration, its extrinsic and intrinsic parameters, provide an average error of $48.62 \mathrm{~m}$ and $22.84 \mathrm{~m}$ in the location of the photocentres for the FIDASE and Argentine flight, respectively. The obtained plannimetric distribution of the cameras and their overlaps (Fig. 8) shows a multiplicity greater than 3 in the area of interest. Once the processign is supported on the 37 GCPs, the total location error in the points on the ground decreases to $5.79 \mathrm{~m}$ and $4.72 \mathrm{~m}$, values that are within the limits recommended in the Koppe tables for the planimetric accuracies. Locally, these errors exceed the overall average in the area north of Kendall Terrace to Macaroni Head, and south of Costa Recta at Baily Head, probably due to the difficulty of properly locating the GCPs in those areas, because of the orientation of the shadow.

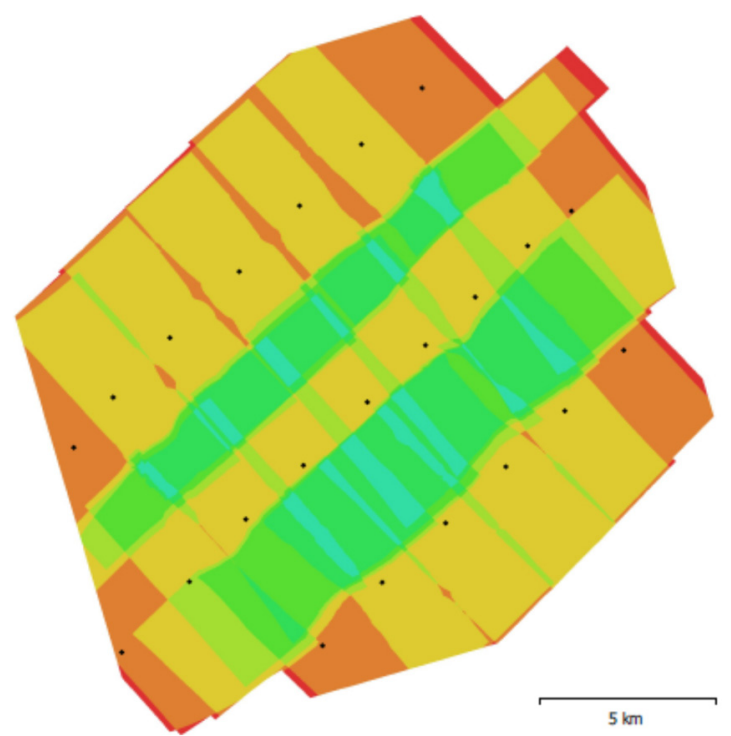

(a)

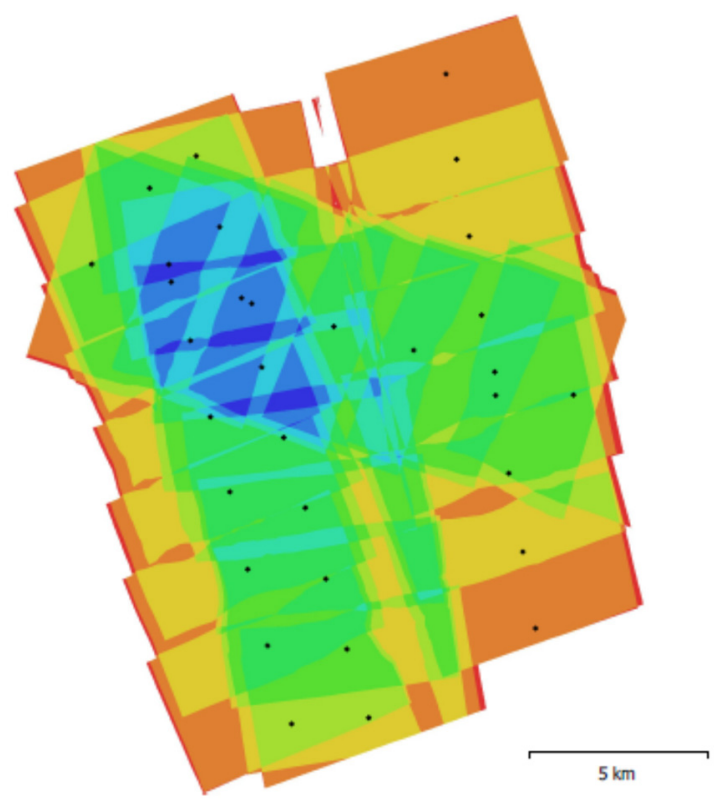

(b)

Figure 8: Camera locations and image overlap: a) FIDASE; b) Argentinean photogrammetric flights.

From the 3DSPC, the 3DDPC is calculated by means of depth maps. These average maps allow to capture the depth, the distance of the surfaces of objects in a scene, or the distance at which a pixel, recognised in several 
images, is located from one point of view (in this case, the aircraft camera). From the camera orientation of the 3DSPC, the depth map can be calculated by trigonometry between the rays projected from the camera origin(s) to the image pixels, and the intersection between the rays from different images determines a depth value, which allows the projection of a $2 \mathrm{D}$ pixel coordinate into the $3 \mathrm{D}$ space, displayed as a depth map. The use of depth maps allows the calculation of a $3 \mathrm{D}$ component not found in $2 \mathrm{D}$ images alone, improves filtering during dense stereo adjustment, and reduces noise on the final surface while preserving the detailed structures of the scene. The orientations and relative positions of multiple cameras allow the calculation of different depth maps, which can be combined to determine a statistically probable 3D position for any pixel found in overlapping images. For each point in the final 3DDPC, the number of combined depth maps that contribute is recorded and presented as a confidence value. This confidence value can then be used to further filter out low confidence points and discard them from the DTM or TIN retrieval process. The set of parameters used to control the quality of the process and the results obtained are listed in Table 2. In addition to this parameter set, it is possible to define other parameters on the 3DDPC, such as DPGFs (Javadnejad et al. 2021) that include proximity to keypoint features, distance to GCPs, angle of incidence, camera separation distance, number of overlapping images, brightness index, and darkness index, which could be assessed by Sfm-MVS processing of historical images.

Table 2: Summary of the quality control parameters obtained for each flight.

\begin{tabular}{c|c|c}
$\begin{array}{c}\text { Quality control } \\
\text { parameter }\end{array}$ & $\begin{array}{c}\text { FIDASE Hunting } \\
\text { UK 1956 }\end{array}$ & $\begin{array}{c}\text { Argentinean Army } \\
1968\end{array}$ \\
\hline DTM pixel size & $1.78 \mathrm{~m} / \mathrm{px}$ & $2.64 \mathrm{~m} / \mathrm{px}$ \\
Ortho pixel size & $0.773 \mathrm{~m} / \mathrm{px}$ & $1.205 \mathrm{~m} / \mathrm{px}$ \\
No. pts. 3DSPC & 10176 & 24597 \\
No. pts. 3DDPC & 45429979 & 24471902 \\
RMSE $_{\text {image }}$ & $48.62 \mathrm{~m}$ & $27.84 \mathrm{~m}$ \\
Easting & $3.93 \mathrm{~m}$ & $3.45 \mathrm{~m}$ \\
Northing $_{\mathrm{GCP}}$ error & $3.60 \mathrm{~m}$ & $2.75 \mathrm{~m}$ \\
Altitude & $1.66 \mathrm{~m}$ \\
RMSE $_{\mathrm{GCP}}$ & $2.25 \mathrm{~m}$ & $4.72 \mathrm{~m}$ \\
$\mathrm{RU}_{\max }$ & $5.79 \mathrm{~m}$ & 8.64 \\
$\mathrm{PA}_{\max }$ & 7.05 & 8.99 \\
RE $_{\max }$ & 5.99 & $4.01 \mathrm{px}$ \\
RMSE $_{\mathrm{RE}}$ & $5.98 \mathrm{px}$ & $0.645 \mathrm{px}$ \\
Cov $_{\min }$ & $0.693 \mathrm{px}$ & 1.1 \\
Cov $_{\max }$ & 1.3 & 9.4 \\
& 6.4 &
\end{tabular}

Using the depth maps (Fig. 9), instead of using the 3DDPC to obtain the TIN, we work directly with the depth map data, which allows us to reconstruct an exceptionally detailed geometry by using all available information. The result of the process fills gaps better than using 3DDPC and the definition of the surface relief appears clearer. The quality control of the obtained TIN can be done with the model confidence which is collected as an additional parameter on the TIN, and which allows to identify parts of the photogrammetric scene that are less accurate or with values in the order of $10^{\circ}$, e.g. interpolated areas have 0 confidence, then low overlap areas, etc.

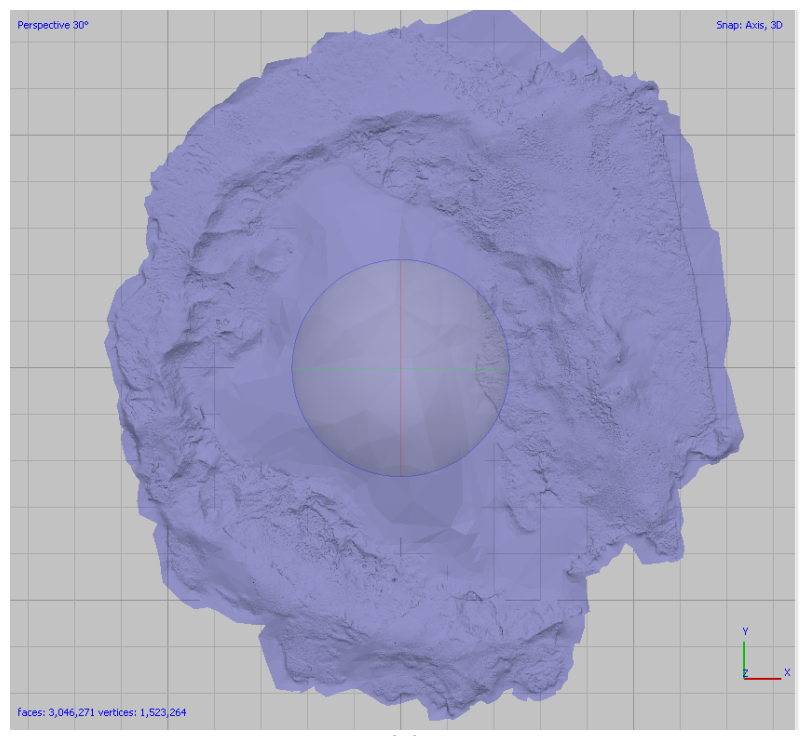

(a)

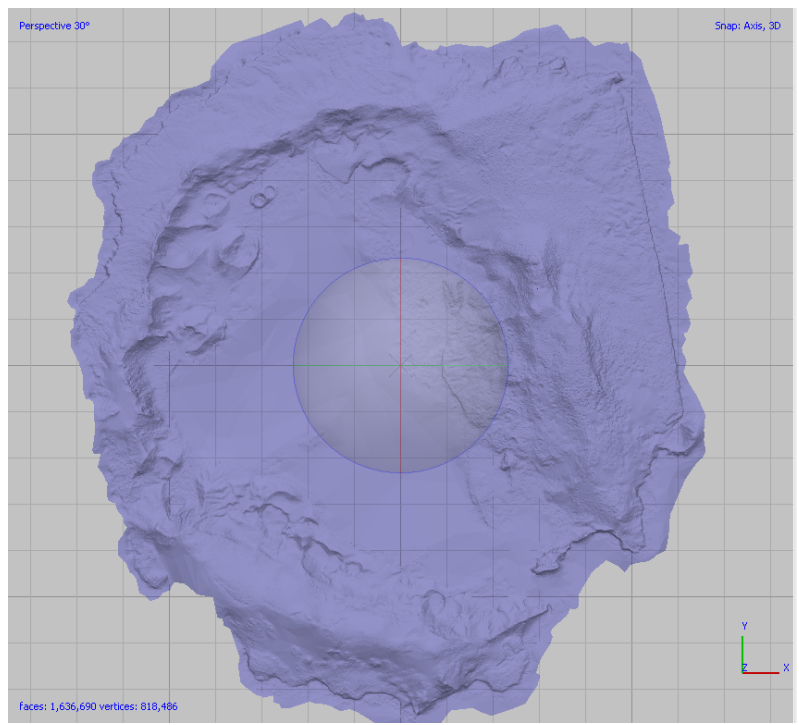

(b)

Figure 9: Triangulation irregular network TIN: a) FIDASE; b) Argentinean photogrammetric flights.

The results obtained with the depth maps in TIN have served as an incentive to use them also in the calculation of the DTM through TIN (Fig. 10). If 3DSPC is used directly, the results obtained show an extremely irregular surface, with numerous bumps, hollows, and unnatural prominences. The pixel size obtained is within the resolution limits for a 1:25 000 mapping, from which it can be accurately estimated down to $1 / 5$ of a millimetre.

Finally, the orthomosaic (Fig. 11) of each flight has been obtained, taking as support the previous DTM and applying a refinement to the seam lines between the images that compose the orthorectified collage. The combination of this orthoimage with the DTM allows us to identify and quantify at a glance the morphometric changes produced in the area of the last eruptions (Hunt et al. 2020) in the NE of Foster Bay (Fig. 12). It will also 
help to estimate other changes related to active geomorphological processes such as coastal recession or land erosion and gullying near the Argentinean and Spanish Antarctic bases and to study their possible relationship with the deterioration of permafrost and the possible effect of climate change since historical times.

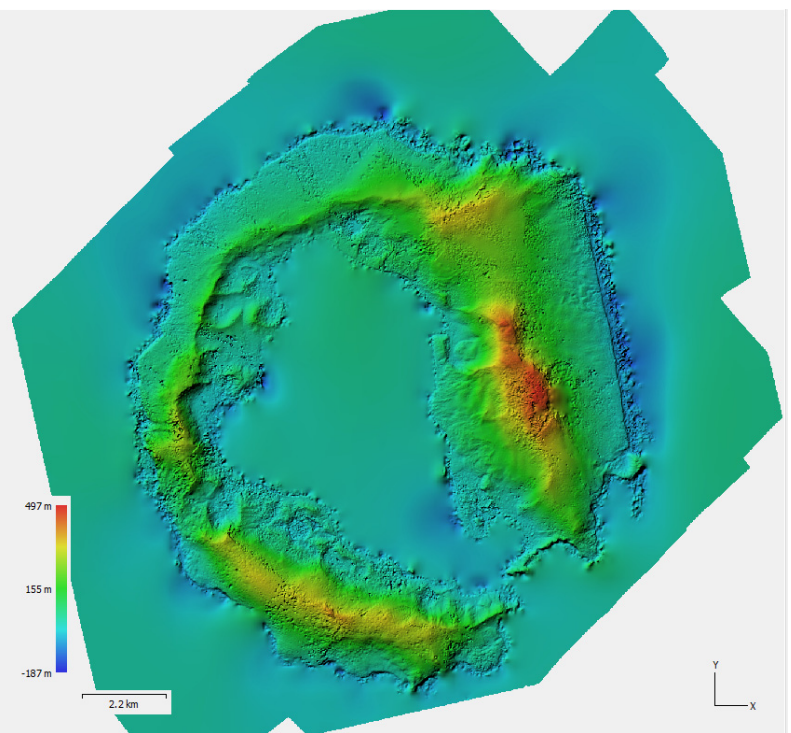

(a)

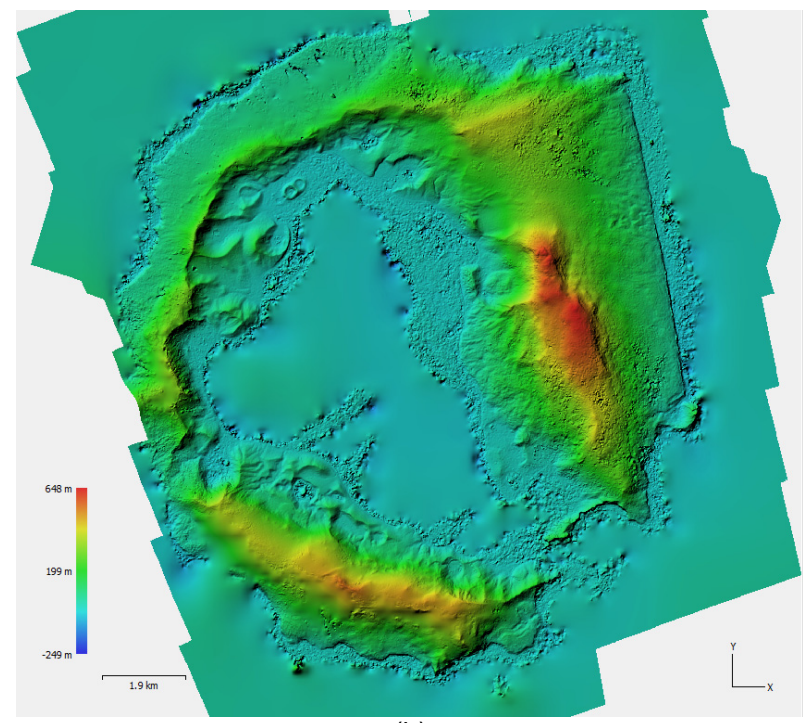

(b)

Figure 10: Digital terrain model (DTM): a) FIDASE; b) Argentinean photogrammetric flights.

\section{Conclusions}

The photogrammetric processing of the 22 and 33 digitised images from the second pass of the FIDASE expedition over Deception Island on 19/12/1956 and the 1967 posteruption aerial photogrammetric survey flight by the Argentine Navy on 21/01/1968 using SfM-MVS techniques implemented in Agisoft Metashape, has made it possible to obtain a DTM of the island in 1956 and 1967 with a higher or comparable quality than the 1960 D.O.S. topographic map with the additional advantage that the products are in digital format and have been obtained from the original sources. With the DTM we have obtained what may be the first orthorectified photomosaic of the island in 1956, which, used in conjunction with the DTM, will allow us to evaluate not only qualitatively but also quantitatively the changes that the island has undergone since then.

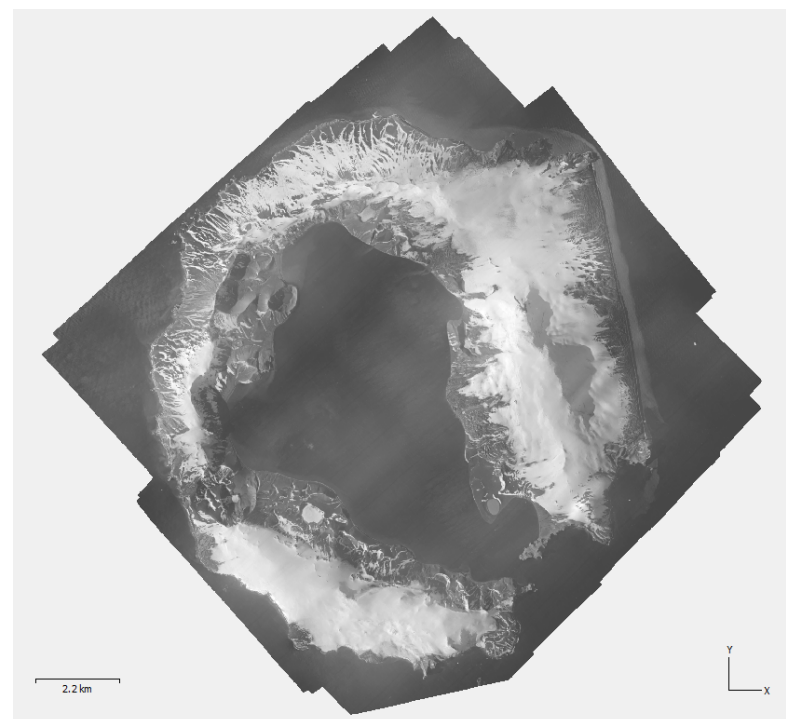

(a)

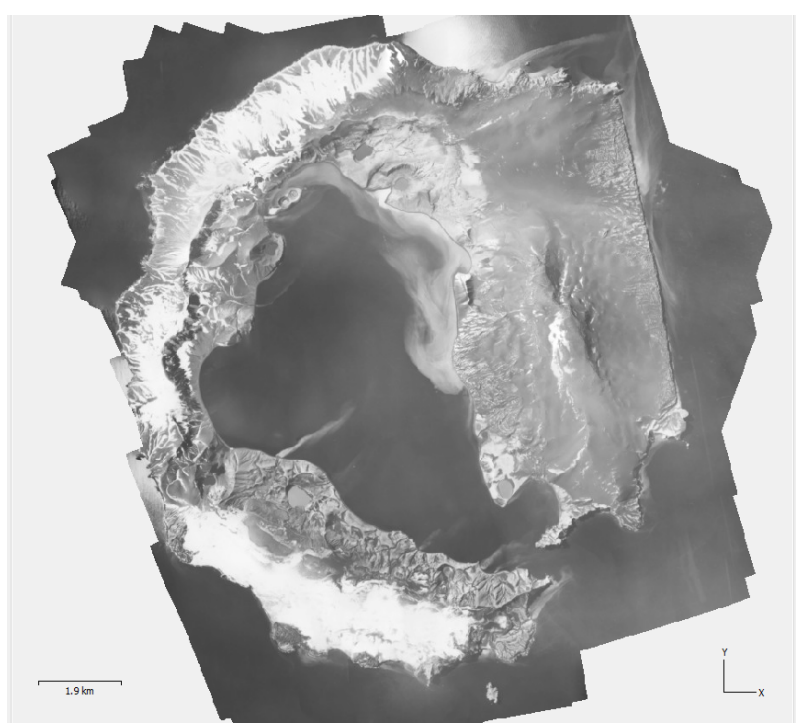

(b)

Figure 11: Orthomosaic using DTM: a) FIDASE; b) Argentinean photogrammetric flights.

The procedure presented for the photogrammetric restitution of the historical images has proved to be efficient, in view of the planimetric and altimetric errors of the results, and despite the fact that the images were not photogrammetrically scanned and presented important deficiencies in terms of quality and sharpness. Even the matching of images with areas that were difficult to link, especially ice-covered areas, where relief variations become indistinguishable by contrast, has been possible, while in high relief areas there is an excessive amount of contrast between the brightness or reflected light from the snow compared to the vertical faces of the exposed rock and the deep shadows cast by the mountains. Currently, the team is also working with the English 1:12000 (1979), and Chilean 1:30000 (1986) flights using the procedure presented. The authors are not aware of any other flights of lesser relevance, for which significant results have been published. The DTMs and orthoimages obtained 
from the 4 flights will be used to complete the historical catalogue of other geomorphodynamic processes that occurred on the island during its geodynamic evolution in the recent past.

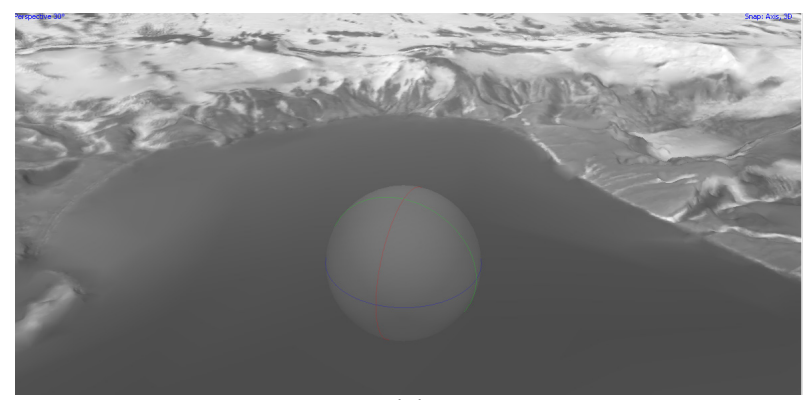

(a)

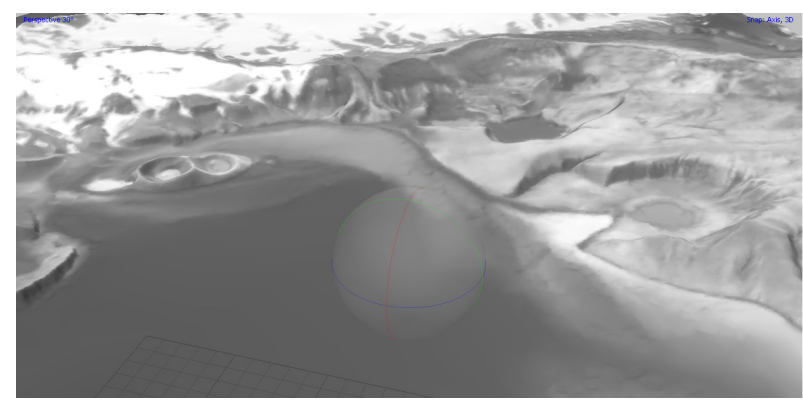

(b)

Figure 12: Orthomosaic drapped over DTM: a) FIDASE: b) Argentinean photogrammetric flights.

\section{References}

BAKER, P., MCREATH, M.A., HARVEY, M.R., ROOBOL, M.J. and DAVIES, T.G., 1975. The geology of the South Shetland Islands: V. Volcanic evolution of Deception Island. British Antarctic Survey Scientific Reports, 78, 107 p.

BERROCOSO, M., TORRECILLAS, C., JIGENA, B., and FERNANDEZ-ROS, A., 2012. Determination of geomorphological and volumetric variations in the 1970 land volcanic craters area (Deception Island, Antarctica) from 1968 using historical and current maps, remote sensing and GNSS. Antarctic Science, 24(04), pp. 367-376. DOI: 10.1017/S0954102012000193.

DOS. 1960. Directorate of Overseas Surveys, Deception Island, D.O.S. 310, scale 1:25,000 (map), Great Britain.

GIROD L, NIELSEN NI, COUDERETTE F, NUTH C. and KÄÄB A., 2018. Precise DEM extraction from Svalbard using 1936 high oblique imagery. Geosci Instrum Methods Data Syst., 7, pp. 277-288. DOI: 10.5194/gi-7-277-2018.

HARTLEY, R., and ZISSERMAN, A., 2004. Multiple View Geometry in Computer Vision (2nd ed.). Cambridge: Cambridge University Press. $655 \mathrm{p}$.

HUNT, J.A., MATHER, T.A., and PYLE, D.M, 2020. Morphological comparison of distributed volcanic fields in the Main Ethiopian Rift using high-resolution digital elevation models. Journal of Volcanology and Geothermal research, 393(1), 106732. DOI: 10.1016/j.jvolgeores.2019.106732.

HYDROGRAPHIC DEPARTMENT ADMIRALTY, 1949. South Shetland Islands, Deception Island, Naval Hydrographic Unit, FIDS, 1948/9, Great Britain, E8566 Press, 31s (unpublished report).

JAMES, M.M., 2017. SfM-MVS PhotoScan image processing exercise. The IAVCEI 'Drone' workshop, held on 13th August. Portland, USA.

JAVADNEJAD, F., SLOCUM, R. K., GILLINS, D. T., OLSEN, M. J., and PARRISH C. E., 2021. Dense point cloud quality factor as proxy for accuracy assessment of image-based 3D reconstruction. J. Surv. Eng., 147(1), 04020021. DOI: 10.1061/(ASCE)SU.1943-5428.0000333.

LIE - ROPERO, M.A., 2015. Proyecto de estudio de afecciones morfológicas en la base Gabriel de Castilla en isla Decepción - Antártida. Madrid: Laboratorio de Ingenieros del Ejército "General Marvá", INTA - Ministerio de Defensa. 264 pages.

MAYER, C., GOMES PEREIRA, L. M. and KERSTEN, T., 2018. A Comprehensive Workflow to Process UAV Images for the Efficient Production of Accurate Geoinformation. CNCG2018 - IX Conferência Nacional de Cartografia e Geodesia, Amadora, Portugal, Oct. Pp. 25-26. 
MOTT, P.G., 1986. Wings over Ice: The Falkland Islands and Dependencies Aerial Survey Expedition; Peter Mott: Long Sutton, UK,167 pages.

RIQUELME A., SOLDATO M.D., TOMÁS, R., CANO, M., BORDEHORE, L., and MORETTI, S., 2019. Digital landform reconstruction using old and recent open access digital aerial photos. Geomorphology, 329, pp. 206-223.

SINGH, K.K. and FRAZIER, A.E., 2018. A meta-analysis and review of unmanned aircraft system (UAS) imagery for terrestrial applications. Int. J. Remote Sens., 39, pp. 5078-5098. DOI: 10.1080/01431161.2017.1420941

TORRECILLAS, C., M. BERROCOSO, M., PÉREZ-LÓPEZ, R., and TORRECILLAS, M.D., 2012. Determination of volumetric variations and coastal changes due to historical volcanic eruptions using historical maps and remote-sensing at Deception Island (West-Antarctica). Geomorphology, 136, pp. 6-14.

ULLMAN, S., 1979. The interpretation of structure from motion. Proceedings of the Royal Society of London, 203(1153), pp. 405-426. 